
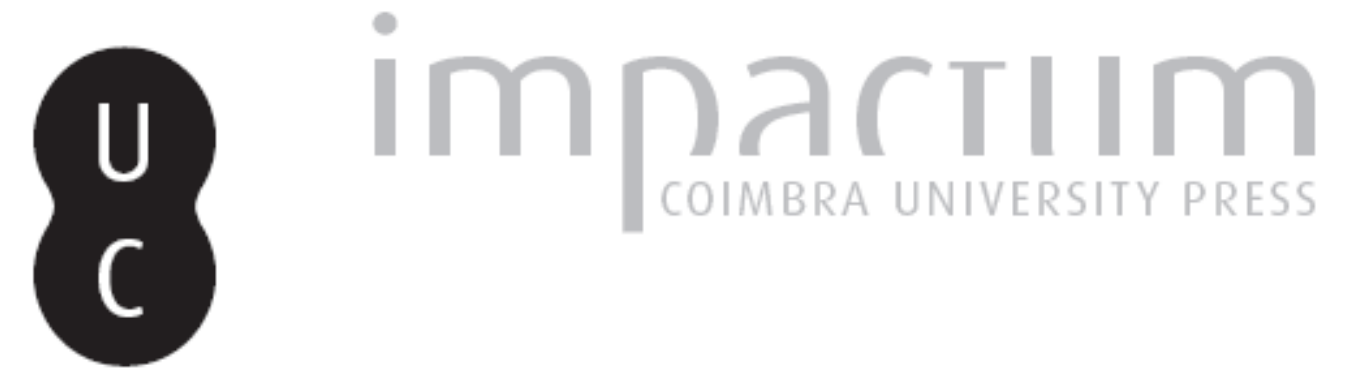

\title{
[Recensão a] Marques, António. A Filosoa e o Mal: Banalidade e Radicalidade do Mal de Hannah Arendt a Kant
}

Autor(es): $\quad$ Uchôa, Marcela da Silva

Publicado por: Imprensa da Universidade de Coimbra

URL persistente:

URI:http://hdl.handle.net/10316.2/42854

DOI:

DOI:http://dx.doi.org/10.14195/0872-0851_50_9

Accessed : $\quad$ 26-Apr-2023 13:28:44

A navegação consulta e descarregamento dos títulos inseridos nas Bibliotecas Digitais UC Digitalis, UC Pombalina e UC Impactum, pressupõem a aceitação plena e sem reservas dos Termos e Condições de Uso destas Bibliotecas Digitais, disponíveis em https://digitalis.uc.pt/pt-pt/termos.

Conforme exposto nos referidos Termos e Condições de Uso, o descarregamento de títulos de acesso restrito requer uma licença válida de autorização devendo o utilizador aceder ao(s) documento(s) a partir de um endereço de IP da instituição detentora da supramencionada licença.

Ao utilizador é apenas permitido o descarregamento para uso pessoal, pelo que o emprego do(s) título(s) descarregado(s) para outro fim, designadamente comercial, carece de autorização do respetivo autor ou editor da obra.

Na medida em que todas as obras da UC Digitalis se encontram protegidas pelo Código do Direito de Autor e Direitos Conexos e demais legislação aplicável, toda a cópia, parcial ou total, deste documento, nos casos em que é legalmente admitida, deverá conter ou fazer-se acompanhar por este aviso.

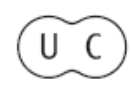




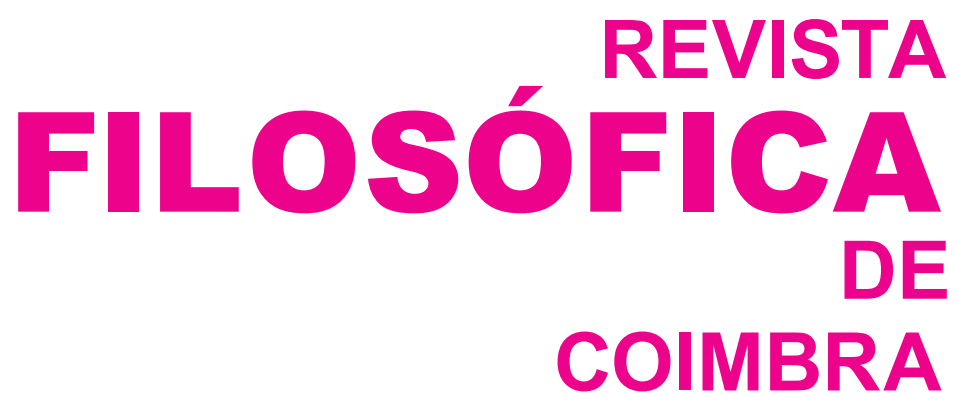

vol. 25 - número 50 - outubro 2016

vol. 25 - número 50 - outubro 2016

Fundação Eng. António de Almeida

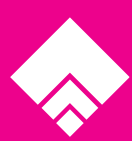


indelével das formas modernas de gnose fundadas na possibilidade de acesso a um ego superior caracterizado pela autonomia face às impressões provenientes da experiência sensorial.

Além de respeitar os mais elevados padrões de edição académica, sendo doravante imprescindível para um trabalho rigoroso sobre o núcleo do pensamento filosófico de R. Steiner, o minucioso trabalho de Clement expõe de modo exaustivo a transmutação operada no mesmo. Apesar de abundantes, os comentários do editor seguem-se aos textos originais, salvaguardando a integridade gráfica e conceptual do texto original. Ao mesmo tempo, a selecção de remissões a autores, temas e polémicas promove uma leitura mais abrangente da obra de Steiner. Seu volumoso caudal informativo não é represado num mostruário de erudição, como tão frequentemente ocorre em edições críticas, mas é posto ao serviço do dínamo da clareza interpretativa. É de referir a título de exemplo o estudo comparativo das anotações que Hartmann efectuou à primeira edição de Filosofia da Liberdade e o modo como nos manuscritos, bem como na edição posterior, Steiner lhes procura responder, por vezes de modo oblíquo (pp. 287ss.).

Em grande medida o volume resgata a obra de Steiner do obscurecimento a que foi votada após a incursão esotérica, a qual justificou também a sua proscrição definitiva dos círculos académicos. Por outro lado, a edição deste volume deixa entrever a possibilidade de uma reconsideração da Antroposofia, em particular as suas reconhecidas expressões na arte, na arquitectura e na terapia, por parte da Filosofia.

Cláudio Alexandre S. Carvalho

Marques, António. A Filosofia e o Mal: Banalidade e Radicalidade do Mal de Hannah Arendt a Kant, Lisboa: Relógio D'água Editora, 2015, 126pp.

O livro A Filosofia e o Mal de António Marques dedica-se de forma salutar à questão do mal na filosofia de Arendt, mais especificamente ao livro da autora: Eichmann em Jerusalém. A análise se desenvolve de forma respeitosa à filósofa, sempre a destacar a importância de sua reflexão enfatizando a grande pensadora política que foi, mas de forma a demonstrar seu domínio ao evidenciar para além dos pontos fortes as fragilidades no discurso da autora.

Dividido em nove capítulos, o livro busca estabelecer um diálogo com as várias problemáticas evocadas pela obra de Hannah Arendt em Eichmann em Jerusalém. Já no primeiro capítulo intitulado: A estranha natureza do Eichmann em Jerusalém - Uma reportagem sobre a banalidade do mal (1963) Choque e incompreensão (pp. 20-24) Marques busca clarificar o percurso nem sempre pacífico acerca da dicotomia entre o mal radical de Kant e o Mal banal de Arendt. Para tanto, lida com os vários aspectos controversos que o livro Eichmann em Jerusalém de Arendt evocou. 
A obra que coloca o sistema nazista como uma máquina burocrática do mal, é o trabalho que a filósofa Hannah Arendt desenvolveu após ter tido a oportunidade de acompanhar de perto o julgamento de Eichmann (uma das lideranças no Holocausto e participante ativo da conhecida Solução Final, onde foram exterminados milhares de judeus) tendo desenvolvido uma série de artigos, que são uma sequência do conjunto de reportagens feitas para a revista New Yorker, posteriormente publicados como livro.

Logo no primeiro capítulo do livro, Marques, então, retoma a discussão acerca da forma como Arendt interpretou a postura de Eichmann deixando claro o motivo pelo qual sua conduta causou revolta especialmente à comunidade judaica. Marques chama atenção ao facto de Arendt ter estabelecido uma diferenciação entre o homem de massa, aquele que cumpre as leis de forma a não se sentir responsável, e o homem que é capaz de realizar um julgamento, pois age sem se sentir responsável pelos seus atos, apenas cumpre ou não uma determinada lei, e faz perceber que a autora entendeu que quem deveria ser julgado era a pessoa de Eichmann e não todo o Regime Nazista em seu nome.

Marques esclarece que para Arendt, Eichmann está envolto no que ela chama de "mal banal" (Por banalidade do mal, ela se referia ao mal praticado no cotidiano como um ato qualquer). Como a filósofa não tomava partido quer fosse no âmbito religioso, ou mesmo em uma esfera ideológica, buscou uma compreensão do que se passava na subjetividade de alguém como Eichmann. António Marques, ao passo que deixa claro o caminho argumentativo escolhido por Arendt, enfatiza que sua postura foi pouco sensível aos "inimagináveis dilemas sem solução dos Conselhos Judaicos". A posição adotada pela filósofa foi tomada como uma total ausência de piedade para com os judeus, por isso mesmo o autor deixa claro que é indissociável a compreensão do mal banal em Arendt sem a ideia do mal radical kantiano.

Contudo, segundo o autor, ao passo que ela desloca a avaliação sobre o mal, do crime monstruoso para a esfera do "mal banal" acaba por causar uma redução do mal radical kantiano (conceito kantiano que aparece no texto $A$ religião dentro dos limites da simples razão) à sua relação com o monstruoso.

Marques não entra em pormenores sobre o mal radical kantiano nesse capítulo, mas deixa claro que será um tema que irá permear toda a problemática exposta no livro.

No segundo capítulo: A autonomia do juízo: independência e exigência de verdade (pp. 25-32), Marques mostra que a pretensão de Arendt era a de reconstruir uma teoria do juízo que viria a substituir a perda dos valores morais e a queda das ordens jurídicas. Assim a banalidade do mal emerge aqui, sobretudo, como a forma que a própria Arendt interpreta a fragilidade humana de criar juízos, entendendo o ser humano como estando imerso por um completo abandono de si mesmo. 
A banalidade do mal, segundo Marques, aponta para um horizonte onde todos somos capazes de cometer atos cruéis, contudo o mal é banal no sentido em que, é superficial, sem profundidade. Dito de outra maneira: não é nunca radical. O que para a filósofa caracteriza o pensamento de Eichmann, que seria literalmente destituído da faculdade de julgar. Seria incapaz, por outras palavras, de perceber. Seria, sobretudo, uma estupidez, como enfatiza António Marques.

No capítulo terceiro denominado $O$ confronto com Gershom Scholem:amor e morte no caminho da liberdade (pp. 34-44), Marques coloca o leitor em contato com a correspondência da filósofa com Scholem (estudioso da Cabala e do Judaísmo) onde se pode perceber para além de testemunhos pessoais a enunciação de princípios filosóficos e de convicções políticas que irão acompanhar Arendt por toda sua obra. A oposição crítica que a filósofa faz a Scholem demonstra um momento de afirmação de autonomia filosófica frente ao messianismo da cabala, mas sobretudo uma autonomia política face ao sionismo. Neste capítulo, Marques enfatiza como na carta a Scholem a filósofa confirma seu afastamento da noção de mal radical, pois a seu ver o que Kant escreveu não vai muito além do mal vulgar que se configura numa ordem psicológica e não metafísica, postura que António Marques critica de forma enfática.

No capítulo quarto A condição humana num impasse e o grande desvio da modernidade (pp. 45-55) Marques usa a obra The Human Condition para demonstrar o percurso feito por Arendt para estabelecer uma crítica radical da modernidade que por um lado avalia a história do homem moderno como afastamento da vida activa completa e autónoma, e por outro lado emerge de forma positiva ao propor uma reafirmação da política através do modelo da pólis antiga: lugar de exercício do discurso e juízo político. Marques chama atenção ainda para o fato de Arendt usar a Crítica da faculdade do juízo de Kant para buscar essa proposta de recriação da antiga esfera política nos moldes gregos, o que para ele está intrinsecamente ligado com sua tese da banalidade do mal.

No capítulo quinto intitulado: A voz de Martin Heidgger - da presença do ser à ausência do mal (pp. 56-66) António Marques mostra uma aproximação de Arendt com Heidegger no que diz respeito a uma postura de distanciamento do juízo ético. Para Arendt a aproximação de Heidegger com o discurso nazista reflete que ele sofre do que ela chama de "impureza", nas palavras de Jaspers (mais críticas) de falta de caráter. É incapaz de auto-reflexão. A leitura de António Marques enfatiza que com Jaspers, Arendt alinha o pensamento, no entendimento de que Heidegger tem em si os mesmos devaneios de Eichmann. Dando ênfase ao lado patológico de muitas das suas afirmações, Heidegger adotou a postura de tantos outros intelectuais importantes da antiga Alemanha de Weimar, que aderiram de forma entusiasmada ao novo regime. Para Marques, Arendt buscou denunciar a aliança formada entre a intelectualidade alemã, permeada por valores morais burgueses, denunciados como categoricamente alienantes e hipócritas, e pela massa alienada (facilmente manipulável, denominados por ela como a ralé). 
Quanto às supostas denúncias de que Heidegger prejudicasse alunos e professores judeus (mencionada na última carta que Arendt escreveu a Heidegger, logo depois de assumida a Reitoria da Universidade de Freiburg, em 1933), Heidegger respondeu-lhe ponto por ponto, negando categoricamente tais acusações. Depois disso, eles só voltariam a se relacionar a partir de 1949.

No capítulo VI: A voz de Karl Jaspers sobre a Alemanha - Eichmann, o mal e a liberdade do filósofo (pp 67-82), podemos ter um encontro com diálogos entre Jaspers e Arendt através das correspondências que trocavam que acabam por clarificar a relação de amor e ódio da autora em relação à Heidgger. Em uma das suas cartas a Jaspers, Arendt expõe sua indignação com a expulsão de Husserl da universidade em 1936, devido à sua ascendência judia, uma decisão na qual Heidegger teve participação direta (Heidegger, inclusive, retirou a dedicatória a Husserl do seu mais conhecido trabalho, Ser e Tempo quando este foi reeditado, em 1941). Ato que Marques chama de processo de saneamento global de professores judeus e que causou profunda indignação a Arendt pela expulsão de Husserl.

O que António Marques parece querer mostrar é, sobretudo, que não há lugar para um juízo moral na obra de Arendt. Em determinados momentos a autora se manifesta de forma crítica à postura de Heidgger, em outras situações é branda, quase dócil. Assim, a herança de Heidegger em Arendt nada mais é do que a ausência de uma reflexão ética, que segundo Marques teria impedido a filósofa de compreender a existência e efetivação do mal radical (kantiano) no Holocausto.

No capítulo VII (pp. 81-95), um dos mais elucidativos, do livro, Marques enfatiza a perceptível esperteza de Eichmann visando ascender dentro do regime, o que viria a lhe permitir chegar ao cargo de executor-chefe do Terceiro Reich. $\mathrm{O}$ autor descreve o facto sempre de forma a chamar a atenção para as provas explícitas nos vários escritos que Eichmann fez quando estava na Argentina, sempre buscando mostrar que o carrasco nazi tinha plena consciência do que estava fazendo e da sua participação nos atos criminosos do regime. Em uma frase muito elucidativa, Marques enfatiza a fala de Eichmann: "O arrependimento é para as criancinhas". António Marques usa a frase de Eichmann para mostrar que a tese de Arendt sobre a "banalidade do mal" foi no mínimo um equívoco, a fragilidade do discurso da autora, está especialmente na dificuldade de articulação do seu pensar ético com seu juízo político.

E assim os últimos capítulos que se seguem VIII e IX (pp. 98-122) são a tentativa derradeira de Marques em defender de forma clara, aquilo que tentou de forma análoga elucidar em todo o livro, a saber, o facto de a monstruosidade de Eichmann caracterizar de forma perfeita a compreensão do mal como conceito-chave da vida ética face à esfera do político. Segundo a leitura de António Marques o mal pode sim ser radical, pode perpassar toda a vida ética, contaminando várias esferas da vida activa, se estabelecendo como uma estrutura vulgar da consciência moral, se aproxima assim da compreensão do mal como uma grandeza negativa, dotado de uma existência tão real quanto o bem. 
Assim, ao adotar a postura kantiana, Marques concebe o homem como um ser dotado de uma paradoxal complexidade, uma "sociável insociabilidade". Tendo por natureza, a tendência de competir; sendo fundamental a compreensão do que ele chama de "experiência dual normal" da vida ética, momento onde é possível estabelecermos uma diferenciação entre o bem e o mal. O ideal da existência de um bem continua a se perpetuar de forma contundente, ainda que de facto não o exerçamos.

Nesta recensão, busquei clarificar o caminho percorrido por António Marques em sua obra visando evidenciar os aspectos mais salientes do livro, na tentativa de proporcionar ao leitor uma excelente legibilidade da obra. O autor desenvolve suas argumentações de forma muito clara, contudo apesar de a obra suscitar questões pertinentes e inquietantes acerca do mal (tema do conhecimento e interesse de muitos) é direcionado ao público que já tem uma leitura de Arendt, especialmente do livro Eichmann em Jerusalém, exatamente por se tratar de um conjunto de reflexões acerca da obra.

Marcela da Silva Uchôa

Umbelino, Luís António \& Vieira, Nuno Sousa. Memórias do corpo, tentação do espaço. Coimbra: Círculo das Artes Plásticas de Coimbra, 2015, 106 pp.

Falar de um texto, analisá-lo ou descrevê-lo, nunca terá o mesmo peso do que lê-lo. Ainda mais um texto que fala da memória e do espaço. Que tem profundidade e discute dimensionalidades, movimento, entrelaçamento. O livro do professor Luís Umbelino e do artista plástico Nuno Sousa Vieira constitui-se no segundo volume da Coleção Círculo de Ideias - Textos Teóricos do Laboratório de Investigação do Círculo de Artes Plásticas de Coimbra. Como se vê pela "profissão" dos autores, o primeiro professor do Departamento de Filosofia da Faculdade de Letras, de Coimbra, e o segundo, um artista plástico, é um diálogo amigável acerca do espaço e do "lado espacial da memória", a partir do ponto de vista filosófico e do labor artístico. Como se pode observar na leitura do texto e na leitura das imagens, as duas propostas não se ilustram, nem se parafraseiam, nem se misturam, mas "encontram-se de longe em longe e, no entanto, entendem-se por mediação de uma realidade cujo sentido buscam em conjunto: o próprio espaço" (p. 8). O texto, permeado pelo estilo literário, mas ao mesmo tempo guiado pelo rigor filosófico, a disciplina de um investigador, a precisão e o estilo acadêmico, procura discutir algumas teses a partir de um horizonte secundário para a tradição fenomenológica: "a primazia do espaço em relação ao tempo" (p. 7). A memória espacial antecede a temporal. E tal discussão se dá através de dois vieses, o hermenêutico e o "ontotopológico". 